\title{
Ontogeny, Compartmentation, and Turnover of Spectrin Isoforms in Rat Central Neurons
}

\author{
Robert Siman, Mehrdad Ahdoot, and Gary Lynch \\ Department of Psychobiology and Center for the Neurobiology of Learning and Memory, University of California, Irvine, \\ California 92717
}

\begin{abstract}
A variant of a principal structural protein of erythrocytes, spectrin, is a major neuronal protein. Here we have examined the subcellular and regional distributions, subunit composition, ontogeny, and metabolism of spectrin in rat CNS. While all subcellular fractions, except the mitochondrial, expressed the previously characterized brain form of spectrin (fodrin, or $\alpha \gamma$-spectrin), limited brain regions contained, in cytoplasm, a second Isoform immunologically related to erythrocyte $\alpha \beta$-spectrin. Both $\alpha \gamma$ - and $\alpha \beta$-spectrin are primarily neuronal, as evidenced by immunocytochemistry. The spectrins are distributed between 2 distinct subneuronal compartments: a membrane-associated domain containing $\alpha \gamma$-spectrin in relatively constant amounts across brain regions, and a cytoplasmic domain containing both the $\alpha \gamma$ and $\alpha \beta$ isoforms in widely varying amounts across brain regions. Although forebrain has considerable $\alpha \beta$-spectrin, the diencephalon, mesencephalon, and brain stem are devoid of this isoform. Further evidence for spectrin compartmentation comes from its ontogeny. Membrane-associated $\alpha \gamma$ spectrin is present at birth at its adult levels, but cytoplasmic $\alpha \beta$-spectrin is expressed only following the second postnatal week. Similarly, the 4-fold difference in cytoplasmic $\alpha \gamma$-spectrin content across brain regions develops during the third postnatal week. In this compartment, both spectrin forms may be metabolized in vivo, at least in part, by calcium-activated proteolysis. The presence in mammalian neurons of 2 spectrin isoforms and their compartmentation into distinct domains suggests multiple functions for neuronal spectrin, one of which may be in the stabilization or maturation of forebrain neurons.
\end{abstract}

Neurons are remarkable for the complexity and variety of their morphologies. Neuronal processes often extend for distances thousands of times longer than their diameters and contain hundreds of branch points, placing enormous demand on structural components for maintaining shape integrity. The protein skeleton, lying underneath the membrane and projecting throughout the cytoplasm, is thought to provide for the stability of neuronal processes (Bray and Gilbert, 1981). Therefore,

\footnotetext{
Received Dec. 6, 1985; revised May 27, 1986; accepted July 1, 1986.

We wish to thank $R$. Crump for technical assistance and $\mathbf{G}$. Ivy for advice on the immunocytochemistry. This research was supported by grants from NSF (G.L.) and the Hereditary Disease Foundation (R.S.).

Correspondence should be addressed to Robert Siman, Experimental Station, Bldg. 400, Central Research and Development Dept., E. I. du Pont de Nemours and Co., Wilmington, DE 19898.

Copyright (c) 1987 Society for Neuroscience $0270-6474 / 87 / 010055-10 \$ 02.00 / 0$
}

knowledge of the assembly, organization, and metabolism of skeletal proteins is essential to understanding the molecular basis of neuronal form and function.

While studies of neuronal structural proteins have long been directed at the microtubules, neurofilaments, and actin filaments (Wuerker and Kirkpatrick, 1972), only recently has another system with structural potential been described in neurons. The major component of this system is the rod-shaped protein brain spectrin (also called fodrin), which is an analog of one of the primary constituents of the erythrocyte skeleton (Bennett et al., 1982; Lazarides and Nelson, 1982; Glenney and Glenney, 1983; Goodman and Shiffer, 1983). In neurons, spectrin forms a lining immediately beneath the axolemma (Levine and Willard, 1981) and is present in somata, dendrites, and perhaps postsynaptic densities (Carlin et al., 1983; Lazarides and Nelson, 1983a, b; Zagon et al., 1984). Other components of the erythrocyte skelcton are also present in nonerythroid cell types such as neurons (Kay et al., 1983; Davis and Bennett, 1984; Goodman et al., 1984; Baines and Bennett, 1985), suggesting that spectrin and associates may comprise another prominent neuronal structureregulating system.

The spectrins in various cell types are all heterodimers, possessing a similar but somewhat variable $M_{\mathrm{r}} \sim 240,000$ subunit (240 K; $\alpha$-spectrin) and a largely variable subunit (235 K in most tissues, termed $\gamma$-spectrin or $\beta$-fodrin; $220 \mathrm{~K}$ in erythrocytes, termed $\beta$-spectrin; $260 \mathrm{~K}$ in intestinal epithelia, termed TW260; Glenney and Glenney, 1983; Lazarides and Nelson, $1983 \mathrm{a}, \mathrm{b})$. At least some tissues express 2 of the spectrin isoforms, and in avian CNS, individual neurons can contain both $\alpha \gamma$ - and $\alpha \beta$-spectrins (Lazarides and Nelson, 1983a, b). Furthermore, within these neurons, the 2 spectrin isoforms have different ontogenetic programs and are differentially distributed. Thus, $\alpha \beta$-spectrin appears quite late during devclopment, being expressed initially around the time of synaptogenesis, and is restricted to neuronal perikarya and dendritic processes. In contrast, $\alpha \gamma$-spectrin is synthesized constitutively throughout development and, unlike $\alpha \beta$-spectrin, is axonally transported. This has led to the hypothesis that $\alpha \beta$-spectrin production may be induced during synaptogenesis, when it serves to direct a reorganization of synaptic membrane components, while $\alpha \gamma$-spectrin presumably has a more general structural function (Lazarides and Nelson, 1983a, b; Lazarides et al., 1984).

Although spectrins may be major structural components of mammalian neurons, information about their ontogeny, subcellular and regional distributions, and possible metabolic turnover is not presently available. Moreover, the existence of different spectrin isoforms in mammalian brain has not been 


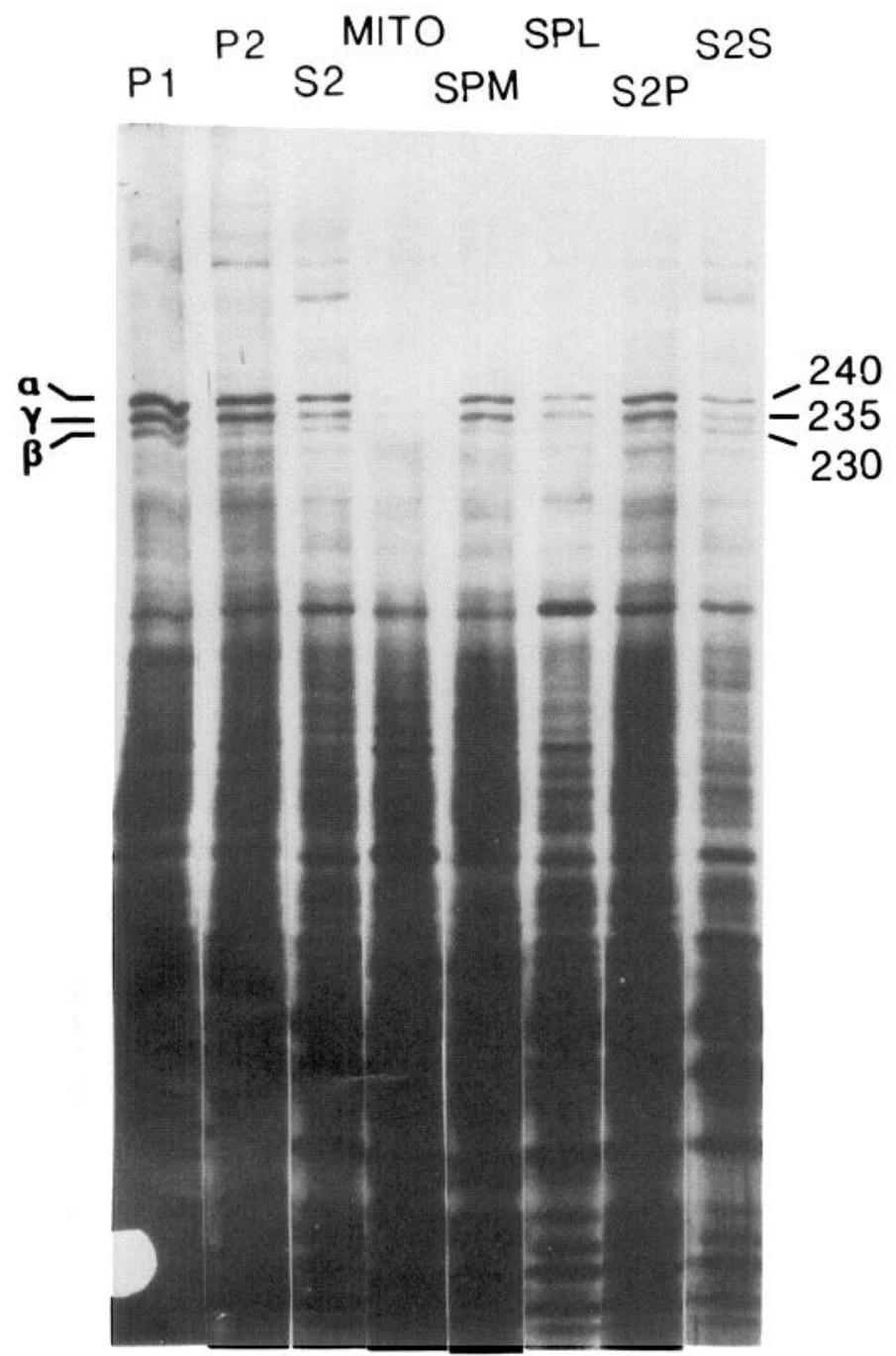

Figure 1. Subcellular distribution of spectrin in rat brain. Cerebral cortex was fractionated into crude nuclear $(P 1)$, crude synaptosomal $(P 2)$, crude microsomal (S2), mitochondrial (MITO), synaptic plasma membrane $(S P M)$, synaptoplasmic $(S P L)$, microsomal $(S 2 P)$, and cytoplasmic $(S 2 S)$ fractions. Polypeptides were separated on $3.5-10 \%$ linear gradient SDS-PAGE and stained with silver as described in Materials and Methods. $\alpha=240 \mathrm{~K}$ polypeptide, $\gamma=235 \mathrm{~K}, \beta=230 \mathrm{~K}$.

established. In order to learn more about the spectrin skeleton in mammalian neurons, we examined the question of spectrin compartmentation, the possible existence of distinct spectrin isoforms, and spectrin ontogenesis and turnover. We have found that rat CNS contains an analog of the erythrocyte $(\alpha \beta)$ as well as the brain $(\alpha \gamma)$ spectrin isoform, and that erythrocyte and a portion of brain spectrin are in a compartment distinct from the remainder of the brain isoform. Furthermore, we report that the former compartment develops only after the bulk of synaptogenesis is completed and present evidence that the spectrins in this compartment are degraded in vivo by calcium-activated proteolysis.

\section{Materials and Methods}

Materials. Hydroxyapatite, diaminobenzidine, Coomassie Brilliant blue $\mathrm{R}$, and $N$-hydroxysuccinimido-biotin were obtained from Sigma. Avidin-peroxidase conjugate, Freund's adjuvants, and goat anti-rabbit IgG were obtained from Cooper. Leupeptin was from Boehringer, casein from Merck, osmotic minipumps from Alzet, and electrophoresis chem- icals and nitrocellulose paper from Bio-Rad. The goat anti-rabbit IgG was biotinylated according to Stahli et al. (1983). $\alpha \gamma$-Spectrin (fodrin) was purified from rat brain membranes as previously described (Siman et al., 1984), while $\alpha \beta$-spectrin was prepared from washed rat erythrocytes according to Marchesi (1974). The $\alpha$-subunit from $\alpha \beta$-spectrin was solubilized with urea and purified using hydroxyapatite as described by Calvert et al. (1980). Adult male Sprague-Dawley rats were used throughout, except for developmental experiments, which employed Sprague-Dawley rats of both sexes (date of birth taken as postnatal day $0)$.

Preparation of antibodies. Antisera were raised in rabbits against either brain $\alpha \gamma$-spectrin (fodrin) or erythrocyte $\alpha \beta$-spectrin. The preparation of rabbit anti-rat brain $\alpha \gamma$-spectrin (antifodrin) has been previously described (Siman et al., 1984, 1985). Antisera to electrophoretically purified $\alpha \beta$-spectrin were prepared by the same method. These sera contained antibodies directed against both the $\alpha$ and $\beta$ subunits, as evidenced by immunoblotting (see below). All antibodies were purified from immune sera by antigen affinity chromatography (Siman et al., 1985). Antibodies specific for erythrocyte $\beta$-spectrin were prepared by removal of antibodies to $\alpha$-spectrin on an $\alpha$-spectrin-Sepharose 4B column. The column was prepared using the cyanogen bromide method (Siman et al., 1984, 1985).

Subcellular fractionation. The indicated regions from adult rat brain were homogenized in $10 \mathrm{vol}$ of $0.32 \mathrm{~m}$ sucrose containing $3 \mathrm{~mm}$ Tris and $0.5 \mathrm{~mm}$ EDTA ( $\mathrm{pH} 7.4)$. The homogenate was centrifuged at $1000 \times$ $g$ for $10 \mathrm{~min}$. The pellets $(\mathrm{Pl})$ were used as crude nuclear fractions, while supernatants were centrifuged at $17,000 \times g$ for $20 \mathrm{~min}$. Supernatants from this step were taken as crude microsomal fractions (S2) or were centrifuged at $40,000 \times g$ for $30 \mathrm{~min}$ to generate microsomal (S2P, pellet) or cytoplasmic (S2S, supernatant) fractions. The crude synaptosomes (P2) were lysed by suspension in 5 vol of $3 \mathrm{~mm}$ Tris $/ 0.5 \mathrm{~mm}$

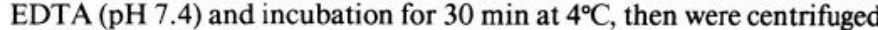
at $8000 \times g$ for $20 \mathrm{~min}$. The brownish pellets (P3) were taken as mitochondrial fractions. Supernatants and buffy coats were pooled and centrifuged at $40,000 \times g$ for $30 \mathrm{~min}$. The pellets were taken as the synaptosomal plasma membrane (SPM) fraction, while supernatants were taken as synaptoplasmic (SPL) fractions. Similar results were obtained by fractionating crude synaptosomes on Ficoll-sucrose density gradients.

For preparation of crude membrane and cytoplasmic fractions, tissues were homogenized in $20 \mathrm{~mm}$ Tris- $\mathrm{HCl}(\mathrm{pH} 7.4) / 1 \mathrm{~mm}$ EDTA and were centrifuged at $40,000 \times g$ for $30 \mathrm{~min}$.

Spectrin quantitation. Polypeptides in the various subcellular fractions were separated by SDS-PAGE using 3.5-10\% linear gradient gels. Each lane was loaded either with $3 \mu \mathrm{g}$ protein and stained with silver (Morrissey, 1981) or with $60 \mu \mathrm{g}$ protein and stained with Coomassie blue (Baudry et al., 1981). Spectrin polypeptides were quantified by densitometry (Baudry et al., 1981). For experiments that employed chronic protease inhibition, the blocker leupeptin was infused continuously into the lateral ventricle via osmotic minipumps as previously described (Ivy et al., 1984). The pumps were filled with the drug at 20 $\mathrm{mg} / \mathrm{ml}$. Control rats received saline through similar minipumps. Animals were sacrificed $10 \mathrm{~d}$ after pump implantation. The presence of leupeptin in the tissue prior to subcellular fractionation did not affect the amount of spectrin subsequently detected.

Immunoblotting and immunoprecipitation. Polypeptides were electrophoretically transferred to nitrocellulose paper according to Towbin et al. (1979). The paper was incubated with $2 \%$ BSA in Tris-buffered saline (TBS; $20 \mathrm{~mm}$ Tris- $\mathrm{HCl}$, pH 7.4, $150 \mathrm{~mm} \mathrm{NaCl}$ ) for $60 \mathrm{~min}$, then with anti-rat brain $\alpha \gamma$-spectrin (diluted 1:500 in BSA/TBS), anti-rat erythrocyte $\alpha \beta$-spectrin (1:100), or anti-rat erythrocyte $\beta$-spectrin (1:50) for $60 \mathrm{~min}$. Blots were washed 3 times ( $5 \mathrm{~min}$ each) with TBS $/ 0.05 \%$ Tween-20 (TTBS) and then incubated for $60 \mathrm{~min}$ with biotinylated goat anti-rabbit IgG (1:250). After being washed as before, blots were incubated for 60 min with avidin-peroxidase conjugate (1:200 in BSA TBS). The blots were washed 3 times with TTBS and twice with TBS, and were treated with a peroxidase substrate solution of $250 \mu \mathrm{g} / \mathrm{ml}$ diaminobenzidine and $0.015 \%$ hydrogen peroxide in TBS.

For immunoprecipitation of brain spectrins, $1 \mathrm{ml}$ of crude microsomes (S2) from cerebral cortex or brain stem was incubated for $60 \mathrm{~min}$ with either anti-brain $\alpha \gamma$-spectrin, anti-erythrocyte $\beta$-spectrin, or preimmune rabbit serum $(0.1,0.4,0.03 \mathrm{ml}$, respectively) in $0.32 \mathrm{M}$ sucrose $20 \mathrm{~mm}$ Tris- $\mathrm{HCl}$ (pH 7.4), $0.5 \mathrm{~mm}$ EDTA, $0.05 \%$ Triton X-100, and $0.05 \%$ Nonidet P-40 (buffer I). Protein A-bearing Staphylococcus aureus (Sigma) were added as a $10 \%$ suspension $(\mathrm{vol} / \mathrm{vol})$ in $0.05 \mathrm{ml}$ buffer I and incubations continued for $60 \mathrm{~min}$. The bacteria were collected by 


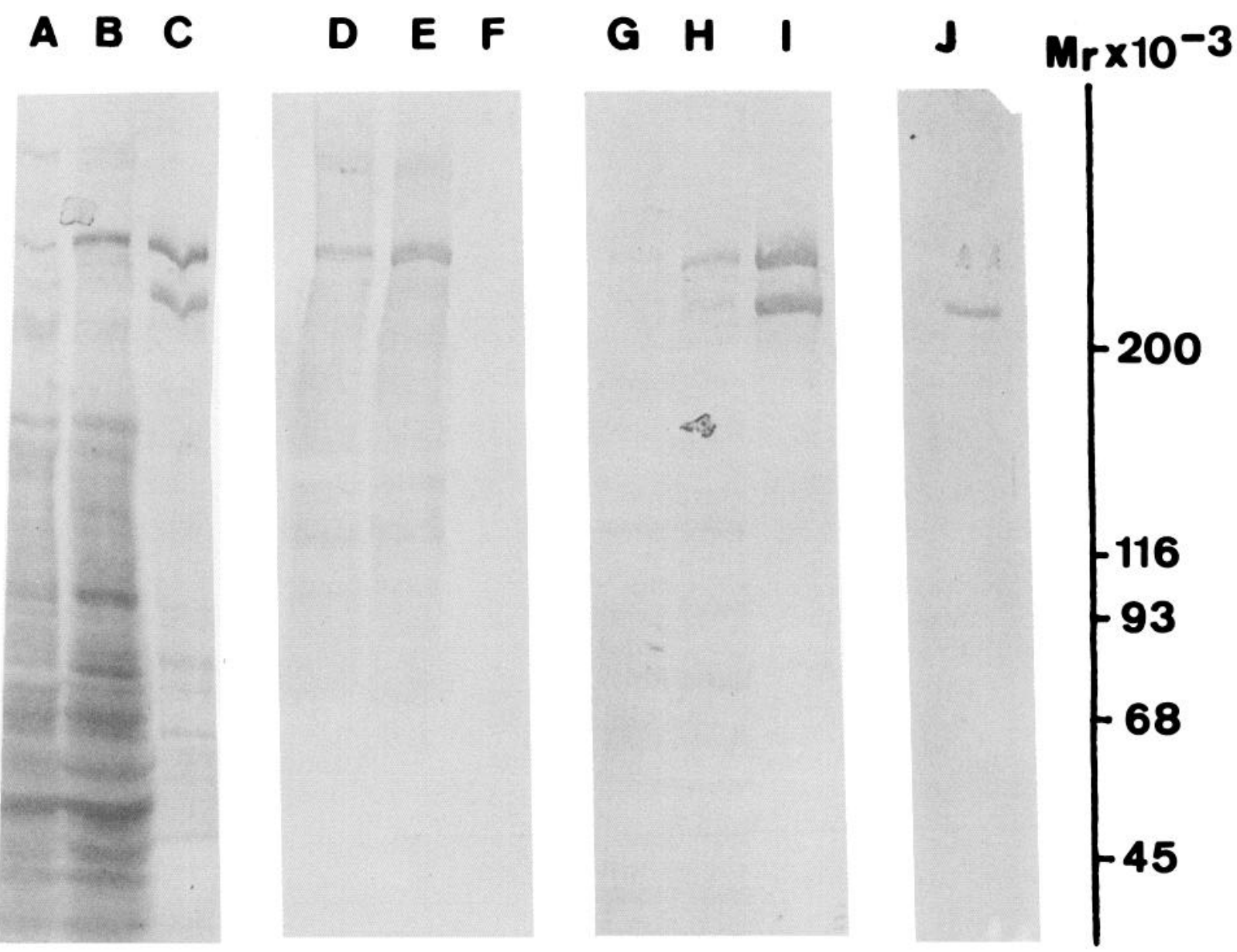

Figure 2. Specificities of anti-brain $\alpha \gamma$-spectrin, anti-erythrocyte $\alpha \beta$-spectrin, and anti-erythrocyte $\beta$-spectrin analyzed by immunoblotting. Lanes $A, D, G$, Brainstem cytoplasm; lanes $B, E, H$, cerebral cortical cytoplasm; lanes $C, I, J$, erythrocyte membranes. Lanes $A-C$ have been stained for total protein with Amido black, lanes $D-F$ with anti-brain $\alpha \gamma$-spectrin, lanes $G-I$ with anti-erythrocyte $\alpha \beta$-spectrin, and lane $J$ with anti-erythrocyte $\beta$-spectrin.

centrifugation at $8000 \times g$ for $5 \mathrm{~min}$ and were washed twice in buffer I by resuspension and centrifugation. Bound proteins were eluted by heating to $95^{\circ} \mathrm{C}$ for $5 \mathrm{~min}$ in electrophoresis sample buffer (Baudry et al., 1981), and bacteria were removed by centrifugation. The eluted proteins were run on $3.5-10 \%$ SDS-PAGE and stained with Coomassie blue.

Immunocytochemistry. Rats were deeply anesthetized with rompun/ ketamine and intracardially perfused with ice-cold PBS followed by $4 \%$ paraformaldehyde in $0.1 \mathrm{~m}$ phosphate ( $\mathrm{pH} 7.4)$. The brains were immersed in fixative for $3 \mathrm{hr}$, then in $25 \%$ sucrose (wt/vol) in $0.1 \mathrm{M}$ phosphate overnight. Sagittal $30 \mu \mathrm{m}$ sections were prepared with a freezing microtome and incubated at $4^{\circ} \mathrm{C}$ for $48 \mathrm{hr}$ in anti-brain $\alpha \gamma$-spectrin (1:60) or anti-erythrocyte $\beta$-spectrin (1:5) in phosphate buffer containing $2 \%$ BSA, $0.01 \%$ sodium azide, and $0.25 \%$ Triton X-100. Bound antibodies were visualized by sequential incubations in biotinylated goat anti-rabbit IgG, avidin-peroxidase, and a peroxidase substrate solution of $300 \mu \mathrm{g} / \mathrm{ml}$ diaminobenzidine and $0.015 \%$ hydrogen peroxide. Essentially no staining was observed if either the primary or secondary antibodies were omitted.

Assay for calcium-stimulated protease (calpain) activity. Cytoplasmic fractions were assayed for proteolysis induced by $1 \mathrm{~mm}$ calcium as previously described (Simonson et al., 1985), using ${ }^{14} \mathrm{C}$-casein as substrate.

\section{Results}

Rat central neurons contain 2 spectrin isoforms

In order to assess spectrin distribution within nerve cells, adult rat brain was fractionated by differential centrifugation and the polypeptide composition of each fraction examined by SDSPAGE. The "brain spectrin" isoform (fodrin) has previously been shown to consist of 2 polypeptides of $M_{\mathrm{r}} \sim 240,000(\alpha-$ spectrin) and 235,000 ( $\gamma$-spectrin) (Glenney and Glenney, 1983; Goodman and Shiffer, 1983; Lazarides and Nelson, 1983a, b). These 2 polypeptides were present in the crude synaptosomal (P2), SPM, microsomal (S2P), SPL, and cytoplasmic (S2S) fractions prepared from rat cerebral cortex, but were only trace components of the mitochondrial (mito) fractions (Fig. 1).

Some cortical fractions contained, in addition to the 240,000 and 235,000 spectrin subunits, a polypeptide of $M_{\mathrm{r}} \sim 230,000$ (Fig. 1). This polypeptide $(230 \mathrm{~K})$ was prominent in the crude microsomal (S2) and cytoplasmic (S2S) fractions, where it was found in approximately equimolar amounts as $\gamma$-spectrin, but was barely detectable in crude synaptosomes, synaptic membranes, and synaptoplasm. More than $90 \%$ of $230 \mathrm{~K}$ fractionaged with cytoplasm.

To determine if the $230 \mathrm{~K}$ polypeptide is a subunit of spectrin, antibodies were raised against brain $\alpha \gamma$-spectrin (fodrin), erythrocyte $\alpha \beta$-spectrin, and erythrocyte $\beta$-spectrin. The specificities of these antibodies are shown in Figure 2. Anti-rat brain $\alpha \gamma$ spectrin bound exclusively to $\alpha$-spectrin on protein blots of cortical (lane E) or brain-stem (D) cytoplasmic fractions and bound weakly to erythrocyte $\alpha$-spectrin (F). Anti-erythrocyte $\alpha \beta$-spectrin recognized both the $\alpha$ and $\beta$ subunits of erythrocyte 


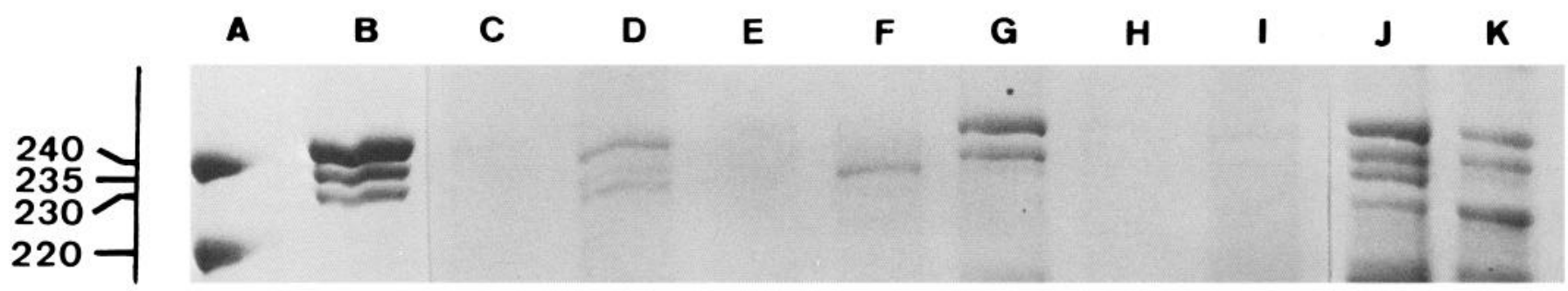

Figure 3. Brain spectrin subunits indentified by immunoprecipitation. Cerebral cortex $(B-E)$ or brain-stem $(G-I)$ cytoplasmic fractions, or cerebral cortical cytoplasm solubilized in SDS $(F)$ were immunoprecipitated with antibodies to brain $\alpha \gamma$-spectrin $(B, G)$, erythrocyte $\beta$-spectrin $(D, F, I)$, or preimmune rabbit serum $(C, E, H)$. Lane $A$ shows as markers erythrocyte spectrin $(240 \mathrm{~K}=\alpha ; 220 \mathrm{~K}=\beta)$, while lanes $J$ and $K$ show total protein from the cortical and brain-stem fractions, respectively. Only the relevant part of the gel is shown. No other polypeptides were specifically precipitated by any of the spectrin antisera.

spectrin (lane I) and bound to cortical $(\mathrm{H})$ and brain-stem $(\mathrm{G})$ $\alpha$-spectrin. Thus, brain $\alpha$-spectrin is immunologically related to but distinct from erythrocyte $\alpha$-spectrin and is clearly different from brain $\gamma$-spectrin and erythrocyte $\beta$-spectrin (see also Glenney et al., 1983; Lazarides and Nelson, 1983a, b). Lane J shows the specificity of the anti-erythrocyte $\beta$-spectrin for this subunit. Under the conditions used here, brain $\gamma$-spectrin and the 230 $\mathrm{K}$ polypeptide transferred poorly to nitrocellulose (lanes $\mathrm{A}, \mathrm{B}$ ), making difficult the assessment of their reactivity with the antibodies.

The subunit composition of brain spectrin(s) was determined by immunoprecipitation. Anti-brain $\alpha \gamma$-spectrin and anti-erythrocyte $\beta$-spectrin were used to precipitate the spectrin(s) from rat cortical or brain-stem cytoplasmic fractions. Antibodies to brain $\alpha \gamma$-spectrin immunoprecipitated, in addition to $\alpha$ - (240 $\mathrm{K})$ and $\gamma$ - $(235 \mathrm{~K})$ spectrin, the cortical $230 \mathrm{~K}$ (Fig. 3, lanes B, G). These polypeptides were precipitated in an approximately 2:1:1 ratio. Furthermore, antibodies specific for erythrocyte $\beta$-spectrin immunoprecipitated 240 and $230 \mathrm{~K}$ in a $1: 1$ ratio (lane D). Therefore, $230 \mathrm{~K}$ complexes with $240 \mathrm{~K}$ in this subcellular fraction. When the fraction was solubilized in SDS to break protein-protein interactions, anti- $\beta$-spectrin immunoprecipitated only $230 \mathrm{~K}$, again demonstrating its specificity for this polypeptide (lane F). Thus, the $230 \mathrm{~K}$ polypeptide is immunologically related to erythrocyte $\beta$-spectrin and forms a $1: 1$ complex in cerebral cortical cytoplasm with $\alpha$-spectrin. This is further supported by the inability of anti-erythrocyte $\beta$-spectrin to immunoprecipitate any polypeptides from brain-stem cytosol, which contains 240 and $235 \mathrm{~K}$ but not $230 \mathrm{~K}$. The $230 \mathrm{~K}$ is not found in brain simply as a consequence of erythrocyte contamination, since it migrates differently from either of the erythrocyte spectrin subunits (compare with Fig. 3, lane A). Moreover, $230 \mathrm{~K}$ likely is not a proteolytic fragment or otherwise modified form of 240 or $235 \mathrm{~K}$ since it is immunologically distinct from these 2 polypeptides. We adopt the nomenclature of Lazarides and coworkers (Lazarides and Nelson, 1983a, b; Lazarides et al., 1984) and will refer to the protein consisting of 240 and $235 \mathrm{~K}$ as brain $\alpha \gamma$-spectrin, and that consisting of 240 and $230 \mathrm{~K}$ as brain $\alpha \beta$-spectrin.

Rat brain tissue sections stained with antibodies to brain $\alpha \gamma$-spectrin or erythrocyte $\beta$-spectrin by an immunoperoxidase procedure showed that spectrin-like immunoreactivity is primarily neuronal (Fig. 4). For example, in cerebellum the Purkinje cell perikarya and dendrites contained abundant and granule cells and white matter axons moderate levels of $\alpha \gamma$ spectrin-like immunoreactivity (A, B). By contrast, no stained profiles of Bergmann glia or astrocytes were apparent. This la- beling is representative of both the $\alpha \gamma$ - and $\alpha \beta$-spectrin isoforms. Antibodies to $\beta$-spectrin, specific for the $\alpha \beta$-isoform, labeled granule cell bodies and, less intensely, the molecular layer but did not stain Purkinje cell bodies or dendrites, white matter axons, Bergmann glia, or astrocytes (C, D). Similarly, these antibodies labeled pyramidal neurons in cerebral cortex and hippocampus but did not appreciably bind to astrocytes in these regions. An immunofluorescent study in mouse brain also found a primary localization of spectrin-like immunoreactivity in neurons (Zagon et al., 1984). Therefore, the subcellular distribution of the spectrins described above and subsequently likely reflects their distribution within neurons.

\section{Regional distribution of spectrin isoforms in neonatal and adult rat brain}

The results presented thus far provide evidence that adult rat brain contains 2 spectrin isoforms, $\alpha \gamma$ and $\alpha \beta$, and that these isoforms are nonuniformly distributed within neurons, with $\alpha \beta$ spectrin being restricted primarily to the cytoplasmic fraction of cortical but not brain-stem tissue. We next determined the distribution of $\alpha \gamma$ - and $\alpha \beta$-spectrins across a number of rat brain subdivisions. In crude cytoplasmic fractions, $\alpha \gamma$-spectrin was ubiquitous, but the $\alpha \beta$-form was limited to forebrain structures and the cerebellum (Fig. 5). Within forebrain, prefrontal cortex, olfactory tubercle, hippocampus, and striatum contained $\alpha \beta$ spectrin, whereas the olfactory bulb did not. In contrast, crude membrane fractions were devoid of appreciable $\alpha \beta$-spectrin (Fig. 5) but contained from 70 to $90 \%$ of the total $\alpha \gamma$-spectrin (data not shown). The amount of spectrins in cytoplasmic fractions varied considerably across brain regions. Forebrain structures contained up to 5 times the amount of spectrins compared with the brain stem or spinal cord (Fig. 6). In contrast, $\alpha \gamma$-spectrin content in crude membrane fractions varied less across brain regions, with brain stem and spinal cord containing about half the spectrin of other regions (Fig. 5).

The data indicate that spectrin is present in 2 compartments in neurons: one (crude cytoplasmic) that contains 2 isoforms in varying amounts across brain regions, and the other (crude membrane) that contains 1 isoform in relatively constant levels across brain regions. To further assess spectrin compartmentation, we examined spectrin ontogenesis in the 2 subcellular fractions. Arguing for spectrin compartmentation in avian neurons, Lazarides and coworkers (Lazarides and Nelson, 1983a, b; Lazarides et al., 1984) found that in retina and cerebellum $\alpha \gamma$-spectrin was present throughout development, but $\alpha \beta$-spectrin only appeared after the initiation of synaptogenesis. We found that spectrin ontogeny in crude cytoplasmic fractions from 

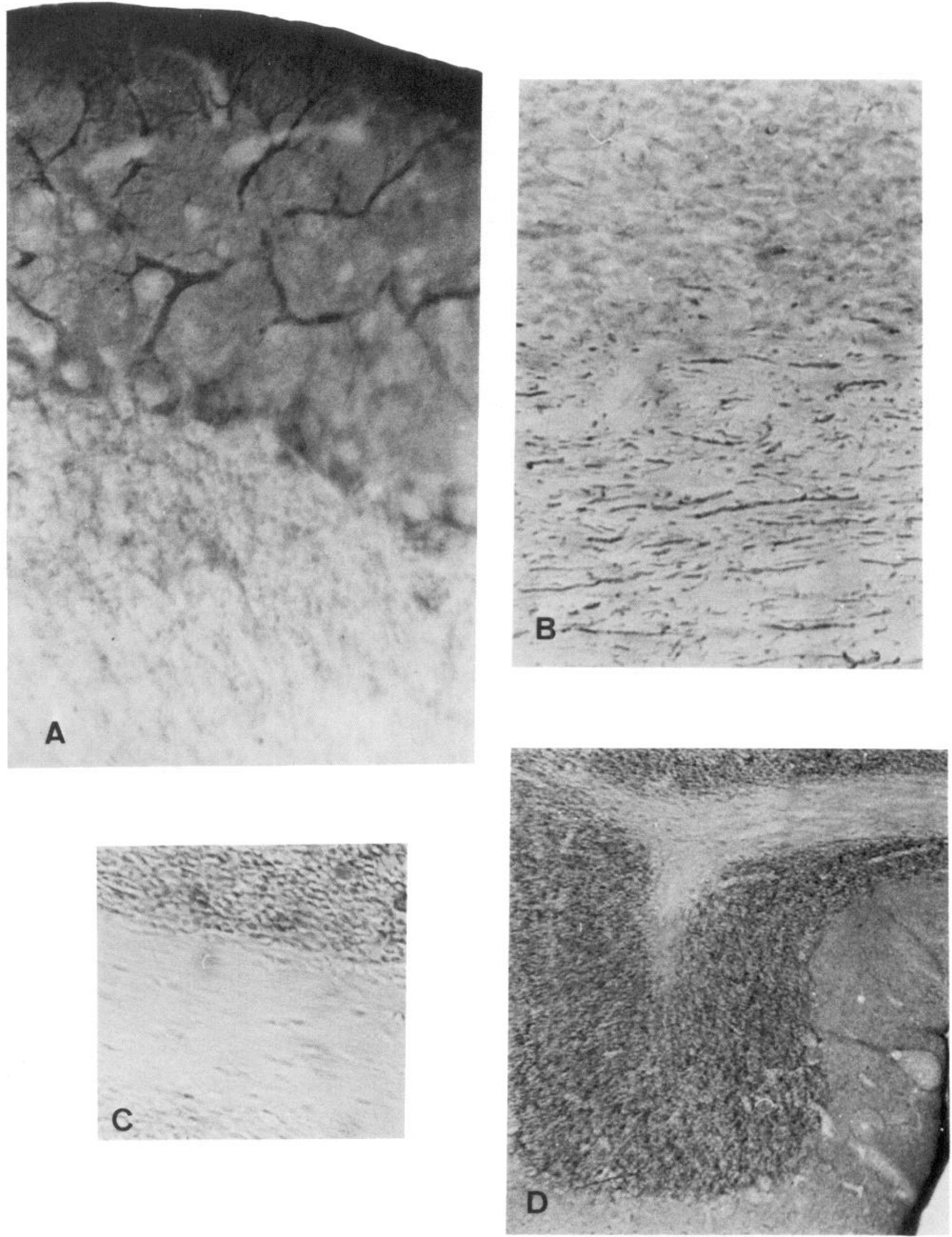

Figure 4. Localization of spectrin-like immunoreactivity in rat cerebellum. $A$ and $B$, Brain $\alpha \gamma$-spectrin; $C$ and $D$, erythrocyte $\beta$-spectrin. $A$, High concentration of $\alpha \gamma$-spectrin-like immunoreactivity ( $\alpha \gamma$-SLI) in Purkinje cell bodies and their dendrites. Bergmann glia in the molecular layer are not apparent. $B$, Labeling of tangentially sectioned axons in white matter. $C, \beta$-SLI is absent from white matter axons but is present in granule cells. $D$, Low-power view showing $\beta$-SLI is heavy in granule cell layer but not as prominent in Purkinje cells. 


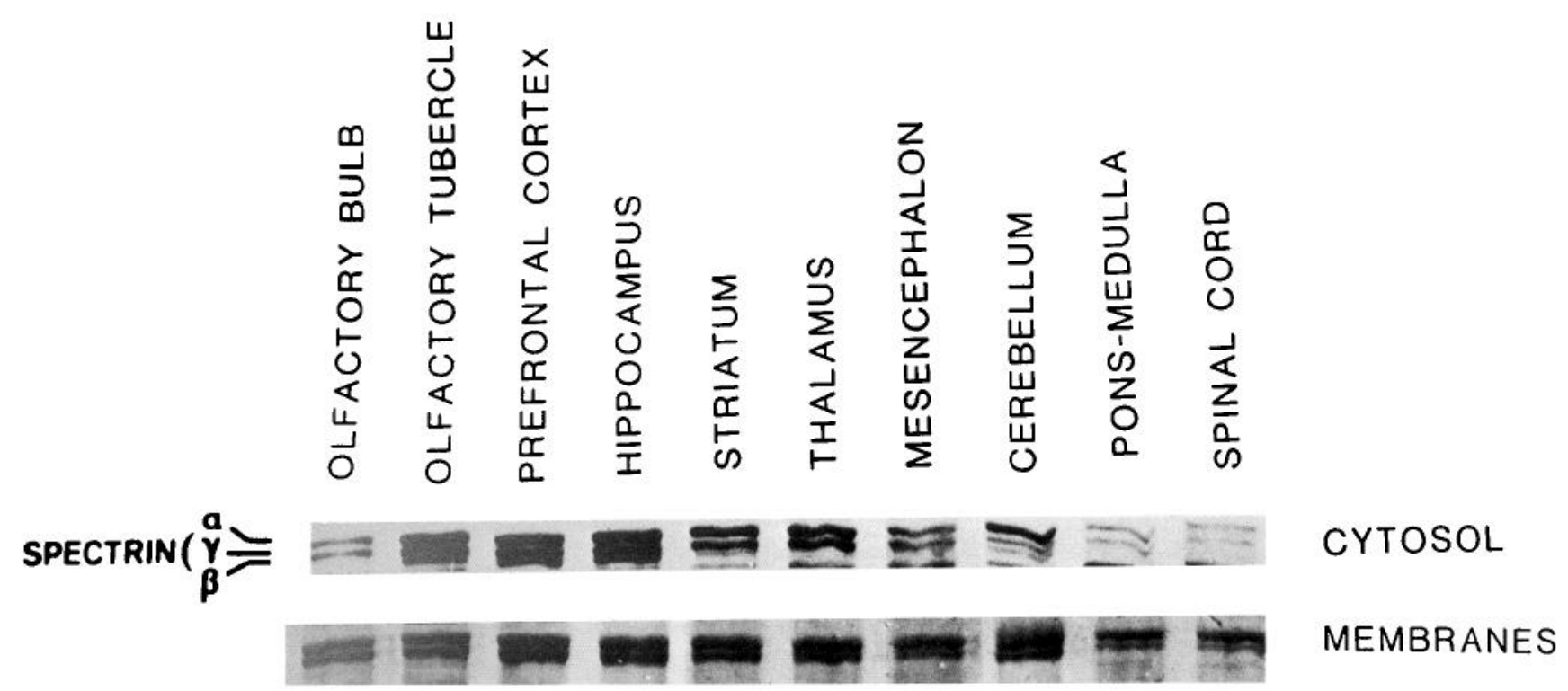

Figure 5. Distribution of spectrin isoforms in rat CNS. Crude cytoplasmic and membrane fractions from the indicated regions were prepared as described in Materials and Methods. Equivalent amounts of protein from each region ( $50 \mu \mathrm{g}$ for cytosols, $25 \mu \mathrm{g}$ for membranes) were run on SDSPAGE, and the spectrin polypeptides were stained with Coomassie blue and quantified by densitometry. Note that while membrane fractions contain substantial $\alpha \gamma$-spectrin, the $\alpha \beta$-form is restricted to the cytosolic fractions of forebrain and cerebellar regions.

rat prefrontal cortex or hippocampus exhibited comparable properties (Fig. 7). While neonates contained $\alpha \gamma$-spectrin, $\alpha \beta$ spectrin was expressed in forebrain under a different developmental program, first appearing after the second postnatal week and reaching adult levels during the fourth postnatal week. The olfactory bulb and brain stem, which do not express $\alpha \beta$-spectrin in adulthood (Fig. 5), were also devoid of this isoform during postnatal development.

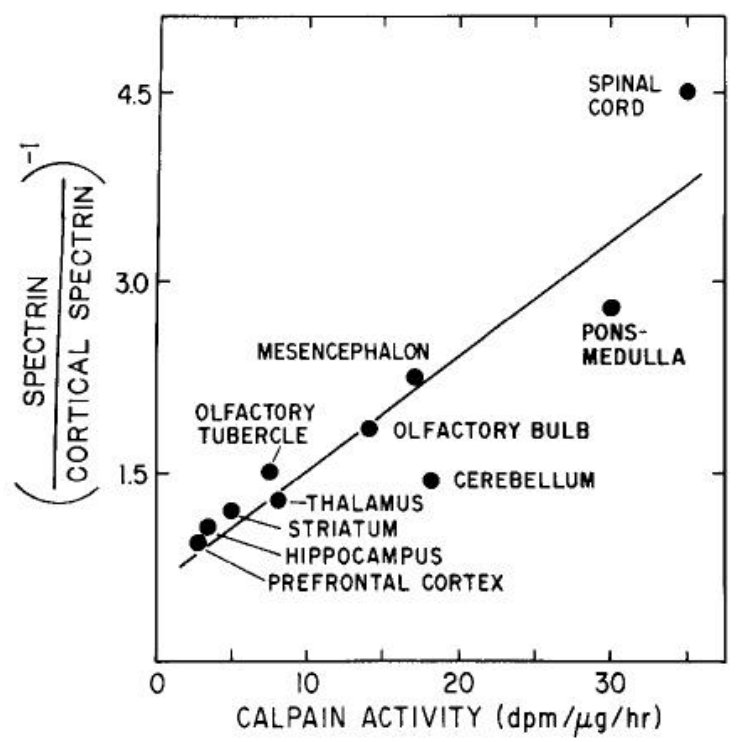

Figure 6. Levels of spectrin and calpain activity in crude cytoplasmic fractions from rat $\mathrm{CNS}$ regions. The fractions were prepared as in Figure 5 . Spectrin polypeptides were quantified by scanning densitometry of stained gels. Spectrin levels are represented as the amount of $\alpha$-spectrin relative to the $\alpha$-spectrin content of prefrontal cortex and are the means from 4 experiments. The data on regional calpain activity are from Simonson et al. (1985) and 3 additional experiments that included the olfactory tubercle and spinal cord.
In addition to $\alpha \beta$-spectrin expression, the establishment of the adult regional distribution pattern of $\alpha \gamma$-spectrin did not begin until after the second postnatal week (Fig. 8, top). Thus, while in adulthood the levels of $\alpha \gamma$-spectrin in brain stem were one-third and in olfactory bulb one-half that in cortex or hippocampus, at birth the brain stem contained more and the bulb comparable levels to cortex. The adult distribution pattern became apparent during the third postnatal week and was firmly established by day 24 . In order that this adult distribution pattern be achieved, $\alpha \gamma$-spectrin levels during development (per unit protein) remained relatively constant in olfactory bulb, decreased in the brain stem, and increased by 3 -fold in cortex and hippocampus (Fig. 9).

Spectrins in the other compartment (crude membrane) do not show the same developmental properties described above. First, the $\alpha \beta$-spectrin isoform was never found in any of the 4 brain regions during postnatal development. Furthermore, $\alpha \gamma$-spectrin content exhibited only small changes as a function of development and never showed the large regional variation present in the cytoplasmic fractions (Fig. 8, bottom). Therefore, the developmental changes in the cytoplasmic fractions are specific for this subcellular compartment and cannot be due merely to a redistribution of spectrins between fractions.

\section{Evidence for spectrin turnover by calcium-activated proteolysis}

Previously, both erythrocyte $\alpha \beta$ - and brain $\alpha \gamma$-spectrins have been shown to be excellent substrates in vitro for calpain I, a high-sensitivity calcium-activated protease (Siman et al., 1984), suggesting that calpain may be involved in the in vivo degradative phase of spectrin turnover. The steady-state level of a protein such as spectrin (Pss) is a function of its rates of synthesis (S) and degradation (D): Pss = S/D. Therefore, if calpain indeed acts to break down neuronal spectrins in vivo, then it follows that those brain regions with the relatively highest calpain levels may have the lowest spectrin levels. This prediction is supported by the results shown in Figure 6 . In the 10 regions of adult rat 


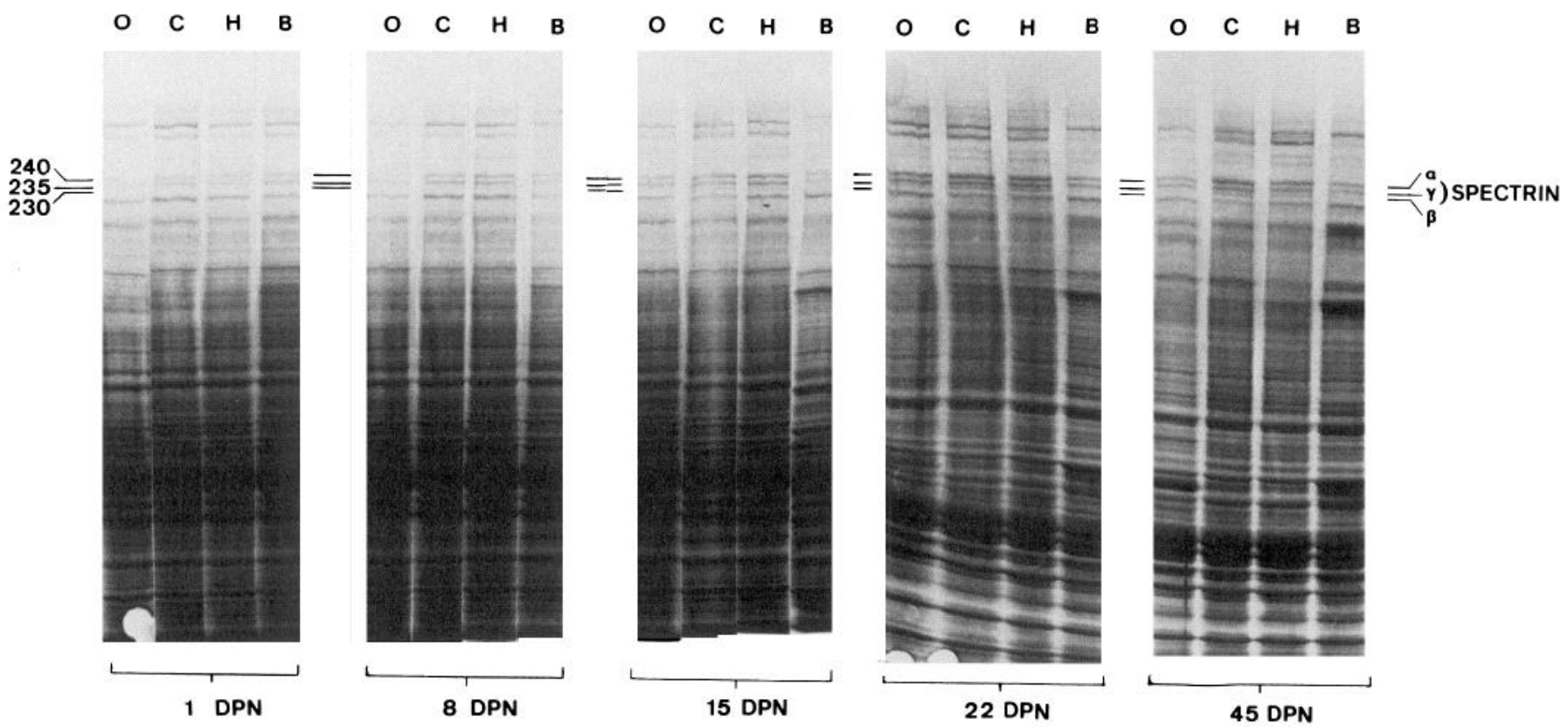

Figure 7. Ontogeny of spectrin isoforms in crude cytoplasmic fractions from rat olfactory bulb $(O)$, prefrontal cortex $(C)$, hippocampus $(H)$, and brain stem $(B)$. Ages of the rats, in days postnatal $(D P N)$, are indicated at the bottom. Note the lack of $230 \mathrm{~K} \beta$-spectrin in cortex and hippocampus prior to day 15, and the differential content of $\alpha \gamma$-spectrin across the brain regions in the adult (day 60), which is not present prior to day 22 .

brain studied, the highest calpain activity levels were found in the spinal cord and brain stem, where activity was more than 10 times that of the prefrontal cortex or hippocampus. Spinal cord and brain stem, conversely, expressed the least $\alpha$-spectrin in the crude cytoplasmic fraction, 4-5 times less than in prefrontal cortex or hippocampus. Diencephalon, mesencephalon, and the olfactory bulb were intermediate in calpain activity and spectrin levels. In this subcellular fraction, $\alpha$-spectrin levels were inversely correlated with calpain activity $(r=0.90)$.

If calpain degrades spectrin in vivo, then a second prediction would be that chronic inhibition of calpain activity should lead to increased levels of spectrin. This prediction is supported by the results shown in Figure 10. Calpain activity was blocked by $10 \mathrm{~d}$ of continuous infusion of the protease inhibitor leupeptin (Murachi, 1983; Siman et al., 1983) into the lateral ventricle. Previously, this treatment has been shown to distribute the inhibitor throughout the brain and to block calpain activity subsequently measured in vitro (Ivy et al., 1984). Chronic leupeptin treatment caused 50-60\% increases in both the $\alpha \gamma$ - and $\alpha \beta$ spectrin forms. Additionally, in brain stem, leupeptin induced substantial increases in polypeptides of $M_{\mathrm{r}} \sim 200,000,150,000$, and 70,000 that comigrated (not shown) with the purified neurofilament triplet. The increased levels of spectrins and neurofilament polypeptides was selective in that most polypeptides, particularly those below $M_{\mathrm{r}} \sim 150,000$, were unaffected by the treatment. As calpain activation in vitro leads to a selective degradation of spectrin and the neurofilaments (and the microtubule-associated protein MAP2; Klein et al., 1981; Zimmerman and Schlaepfer, 1982; Siman et al., 1984), leupeptin likely induced spectrin and neurofilament buildup by an inhibition of calpain.

\section{Discussion}

In this report we present evidence that mammalian neurons contain 2 isoforms of the skeletal protein spectrin. While all regions of the rat CNS contain brain $\alpha \gamma$-spectrin (also known as fodrin or brain spectrin), several forebrain structures and the cerebellum also have an analog of the erythrocyte isoform, $\alpha \beta$ spectrin. The spectrin isoforms are distributed between 2 distinct subneuronal compartments, the evidence being as follows: (1) While many forebrain regions contain both the $\alpha \gamma$ - and $\alpha \beta$ spectrin forms, $\alpha \beta$-spectrin is restricted to the cytoplasmic fractions, whereas $\alpha \gamma$-spectrin is also present in synaptic membrane, synaptoplasmic and microsomal fractions; thus, while crude membrane fractions contain $70-90 \%$ of the total $\alpha \gamma$-spectrin, all detectable $\alpha \beta$-spectrin is in cytoplasmic fractions. (2) Cytoplasmic $\alpha \gamma$ - and $\alpha \beta$-spectrins are differentially distributed across brain regions, while membrane-associated $\alpha \gamma$-spectrin shows a relatively uniform distribution. (3) The differential distribution of $\alpha \gamma$-spectrin in cytoplasmic fractions does not appear until the end of the second postnatal week and is not completely established until week 4 ; the expression of $\alpha \beta$-spectrin also exhibits a late developmental appearance. In contrast, synaptic membrane $\alpha \gamma$-spectrin content shows minor change with post-natal development. (4) The distribution of $\alpha \beta$-spectrin within neurons, detected immunocytochemically with antibodies to $\beta$-spectrin, is more restricted than that of $\alpha \gamma$-spectrin detected, along with $\alpha \beta$-spectrin, with antibodies to $\alpha$-spectrin.

The late expression of $\alpha \beta$-spectrin and changes in $\alpha \gamma$-spectrin content in the cytoplasmic compartment occur only after the bulk of synaptogenesis has begun (Crain et al., 1973; Cowan et al., 1980). This raises the possibility that spectrins in this compartment are induced in response to synapse formation and may serve in the maturation or stabilization of new synaptic complexes. This idea has been previously proposed by Lazarides and coworkers based on compartmentation and ontogeny of spectrin isoforms in avian neurons (Lazarides and Nelson, 1983a, b; Lazarides et al., 1984), but the present results suggest the need for modification of the original hypothesis.

First, $\alpha \beta$-spectrin is not found in appreciable amounts in the 

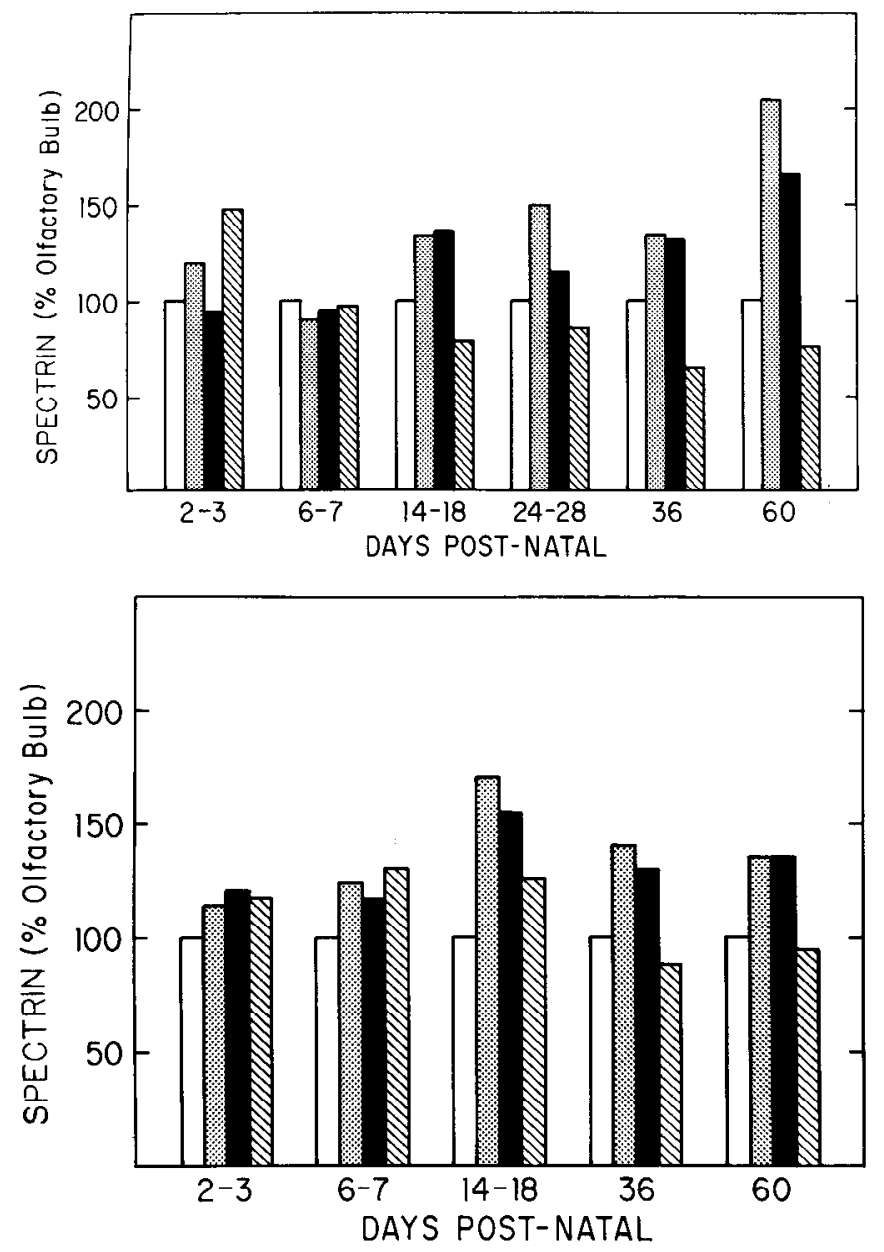

Figure 8. Late ontogeny and differential distribution of cytoplasmic spectrin across brain regions. Top, Spectrin levels in crude cytoplasmic fractions from olfactory bulb (П), prefrontal cortex (國), hippocampus $(\square)$, and brain stem ( $\mathbb{S}$ ) are represented as the amount of $\alpha$-spectrin at each age relative to the $\alpha$-spectrin content of the olfactory bulb, and are the means of 3-5 experiments. Bottom, Ontogeny and distribution of $\alpha \gamma$-spectrin in crude membrane fractions from olfactory bulb ( $\square$ ), prefrontal cortex (⿴囗十), hippocampus $(\mathbb{0})$, and brain stem $(\mathbb{\mathbb { N }})$. Spectrin levels were calculated as described in top.

rat diencephalon, mesencephalon, or brain stem in any subcellular fraction at any time of postnatal development. Therefore, it is unlikely that this isoform plays a general role in the establishment or maintenance of all synaptic contacts. Second, in rat central neurons there appears not to be strict compartmentation of $\alpha \gamma$-spectrin from $\alpha \beta$-spectrin, but rather a domain of $\alpha \gamma$ spectrin that is distinct from a domain containing both $\alpha \gamma$ - and $\alpha \beta$-spectrin. Important functional distinctions, then, may be found between these 2 domains and not between the 2 spectrin isoforms per se. Third, $\alpha \beta$-spectrin is not a major component of rat forebrain synaptic membrane preparations, suggesting either that this isoform is not localized in postsynaptic structures, or at least that it is not tightly associated with synaptic membranes. These data argue against a role for $\alpha \beta$-spectrin in regulating the distribution of synaptic membrane proteins; rather, they suggest that the protein may serve an alternative function. Although the nature of this function is unclear at present, the restriction of $\alpha \beta$-spectrin principally to the telencephalon

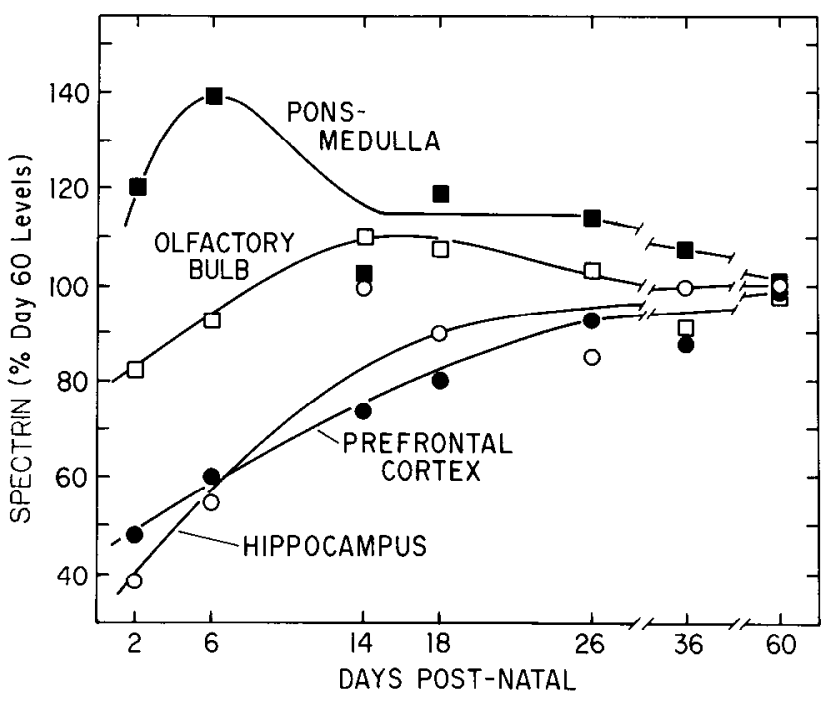

Figure 9. Ontogeny of $\alpha$-spectrin levels as function of adult $\alpha$-spectrin content in crude cytoplasmic fractions from olfactory blub ( $\square$ ), prefrontal cortex $(\Theta)$, hippocampus $(O)$, and brain stem (pons-medulla, $\square$ ). Note that spectrin ontogeny is under different programs in the different regions.

and its late ontogeny suggests that it is involved in maturation or stabilization processcs pcculiar to forebrain neurons.

The compartmentation of spectrins into distinct domains and their late ontogeny in one of these compartments have parallels in other neuronal skeletal systems. For example, the highest molecular weight component of neurofilaments is restricted primarily to an axonal compartment (Baitinger et al., 1983; Weber et al., 1983), while among the microtubule-associated proteins, MAP2 is selectively localized to dendritic tubules (DeCamilli et al., 1984; Huber and Matus, 1984). In addition, the polypeptides that comprise neurofilaments and microtubules are expressed according to distinctive developmental programs, including substantial postnatal alterations in rats (Mareck et al., 1980; Shaw and Weber, 1982; Binder et al., 1984). Changes in skeletal protein expression, occurring after synaptogenesis is virtually complete, are an indication that while synapse formation may initiate the terminal stage of neuronal differentiation, structural remodeling continues well after synaptic contacts are established. These developmentally late structural modifications may have important functional implications, for example, in the capacity of neurons to exhibit plasticity. Injury-induced synaptogenesis shows dramatic declines after the second postnatal week in terms of rapidity and extent of synaptic recovery (Gall et al., 1980; McWilliams and Lynch, 1983). It is reasonable to consider that, during this postnatal period, the changes in structural protein expression and organization could account for the decreased neuronal plasticity.

Skeletal organization likely is in a constantly dynamic state owing to the continual degradation and resynthesis of its protein components. However, despite the apparent ubiquity of protein turnover in eukaryotic cells (Goldberg and St. John, 1976; Hershko and Ciechanover, 1982), there are few data available relating to the turnover of structural proteins in neurons of the adult mammalian brain. Here we have presented 2 pieces of evidence that spectrins in rat central neurons are degraded in vivo, at least in part, by calcium-activated proteolysis. First, spectrin levels in cytoplasmic fractions varied across brain re- 


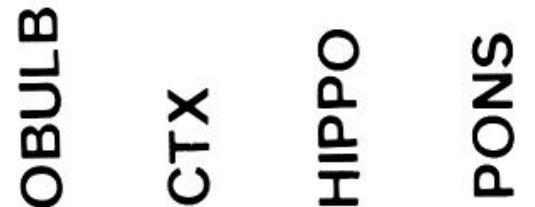 \\ $C L C L C L C L$}

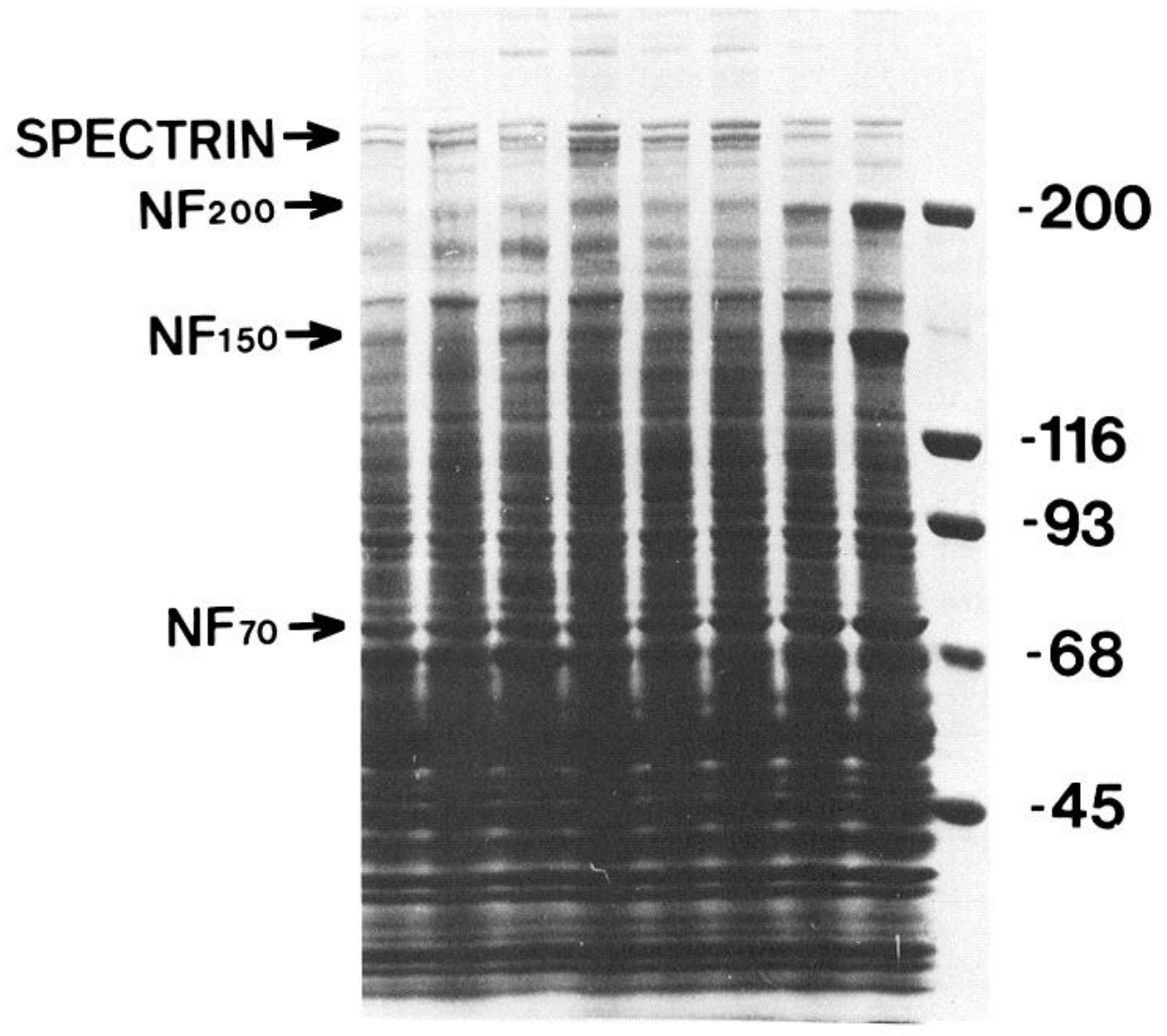

Figure 10. Effect of chronic leupeptin treatment on polypeptide composition of crude cytoplasmic fractions from olfactory bulb $(O B U L B)$, prefrontal cortex $(C T X)$, hippocampus $(H I P P O)$, and brain stem $(P O N S)$. Either saline $(C)$ or leupeptin $(L)$ were delivered into the lateral ventricle for $10 \mathrm{~d}$ via cannulae attached to osmotic minipumps (Ivy et al., 1984). Equivalent amounts of protein were loaded onto each lane. Similar results were obtained in 2 additional experiments. gions in inverse proportion to calcium-dependent protease (calpain) activity (Fig. 6). Second, chronic infusion of a protease inhibitor that blocks calpain activity (Murachi, 1983; Siman et al., 1983) induced increased levels of spectrin (Fig. 10). These results would follow if spectrins in cytoplasmic fractions were in a constant state of turnover, and calpain contributed to the degradative phase of the process. As a caveat, it should be noted that leupeptin will inhibit other proteases in vitro, including many lysozomal enzymes that are considered to play roles in protein turnover in other tissues (Barrett, 1980). However, the leupeptin treatment used here resulted in increased levels of only the spectrins, the neurofilament triplet, and a minority of unidentified polypeptides above $M_{\mathrm{r}} \sim 150,000$, suggesting either that the dose and route of administration used here does not deliver significant amounts to the lysozomes; that turnover of most neuronal proteins is too slow to be affected by $10 \mathrm{~d}$ of protease inhibition, or that lysozomal proteases do not play major parts in the degradation of large numbers of neuronal proteins. Resolution of these issues will be possible only when a number of protease inhibitors with a well-defined and limited specificity are available.
The possible involvement of calpain activity in structural protein turnover in vivo has implications for the functions of both the calpains and their skeletal protein substrates. In vitro experiments have demonstrated that $\alpha \gamma$-spectrin can control the distribution of glutamate binding sites in synaptic membranes and that this control is modified by calpain (Siman et al., 1985). The extent to which these controls generalize to other synaptic proteins and to synaptic membranes in vivo will determine whether spectrins and calpain play major roles in synaptic organization.

\section{References}

Baines, A. J., and V. Bennett (1985) Synapsin I is a spectrin-binding protein immunologically related to erythrocyte protein 4.1 . Nature 315: 410-413.

Baitinger, C., R. Cheney, D. Clements, M. Glicksman, N. Hirokawa, J. Levine, K. Meiri, C. Simon, P. Skene, and M. Willard (1983) Axonally transported proteins in axon development, maintenance, and regeneration. Cold Spring Harbor Symp. Quant. Biol. 48: 791-802.

Barrett, A. J. (1980) Thiol proteinases of human lysosomes. In Enzyme Regulation and Mechanism of Action, P. Mildner and B. Ries, eds., pp. 307-315, Pergamon, Oxford, U.K. 
Baudry, M., M. Bundman, E. K. Smith, and G. Lynch (1981) Micromolar levels of calcium stimulate proteolysis and glutamate binding in rat brain synaptic membranes. Science 212: 937-938.

Bennett, V., J. Davis, and W. E. Fowler (1982) Immunoreactive forms of erythrocyte spectrin and ankyrin in brain. Phil. Trans. R. Soc. Lond. [Biol.] 299: 301-312.

Binder, L. I., A. Frankfurter, H. Kim, A. Caceres, M. R. Payne, and I. Rebhun (1984) MAP2 heterogeneity during rat brain development. Proc. Natl. Acad. Sci. USA 81: 5613-5617.

Bray, D., and D. Gilbert (1981) Cytoskeletal elements in neurons. Annu. Rev. Neurosci. 4: 505-523.

Calvert, R., P. Bennett, and W. Gratzer (1980) Properties and structural role of the subunits of human spectrin. Eur. J. Biochem. 107: 355-361.

Carlin, R. K., D. C. Bartelt, and P. Siekevitz (1983) Identification of fodrin as a major calmodulin-binding protein in postsynaptic density preparations. J. Cell Biol. 96: 443-448.

Cowan, W. M., B. B. Stanfield, and K. Kishi (1980) The development of the dentate gyrus. Curr. Top. Dev. Biol. 15: 103-157.

Crain, B., C. Cotman, D. Taylor, and G. Lynch (1973) A quantitative electron microscopic study of synaptogenesis in the dentate gyrus of the rat. Brain Res. 63: 195-204.

Davis, J. Q., and V. Bennett (1984) Brain ankyrin: A membraneassociated protein with binding sites for spectrin, tubulin, and the cytoplasmic domain of the erythrocyte anion channel. J. Biol. Chem. 259: 13550-13559.

DeCamilli, P., P. E. Miller, F. Navone, W. E. Theurkauf, and R. B. Vallee (1984) Distribution of microtubule-associated protein 2 in the nervous system of the rat studied by immunofluorescence. Neuroscience 11: 819-846.

Gall, C., J. R. McWilliams, and G. Lynch (1980) Accelerated rates of synaptogenesis by "sprouting" afferents in the immature hippocampal formation. J. Comp. Neurol. 193: 1047-1062.

Glenney, J. R., Jr., and P. Glenney (1983) Fodrin is the general spectrin-like protein found in most cells whereas spectrin and the TW protein have a restricted distribution. Cell 34: 503-512.

Glenney, J. R., Jr., P. Glenney, and K. Weber (1983) Mapping the fodrin molecule with monoclonal antibodies: A general approach for rod-like multi-domain proteins. J. Mol. Biol. 167: 275-293.

Goldberg, A. L., and A. C. St. John (1976) Intracellular protein degradation in mammalian and bacterial cells. Annu. Rev. Biochem. 45: 747-803.

Goodman, S. R., and K. Shiffer (1983) The spectrin membrane skeleton of normal and abnormal human erythrocytes: A review. Am. J. Physiol. 244: $\mathrm{C} 121-\mathrm{C} 141$.

Goodman, S. R., L. A. Casoria, D. B. Coleman, and I. S. Zagon (1984) Identification and location of brain protein 4.1. Science 224: 14331436.

Hershko, A., and A. Ciechanover (1982) Mechanisms of intracellular protein breakdown. Annu. Rev. Biochem. 51: 335-364.

Huber, G., and A. Matus (1984) Differences in the cellular distribution of two microtubule-associated proteins MAP1 and MAP2 in rat brain. J. Neurosci. 4: 151-160.

Ivy, G. O., F. Schottler, J. Wenzel, M. Baudry, and G. Lynch (1984) Inhibitors of lysozomal enzymes: Accumulation of lipofuscin-like bodies in the brain. Science 226: 985-987.

Kay, M. M. B., C. M. Tracey, J. R. Goodman, J. C. Cone, and P. S. Bassel (1983) Polypeptides immunologically related to band 3 are present in nucleated somatic cells. Proc. Natl. Acad. Sci. USA 80: 6882-6886.

Klein, I., D. Lehotay, and M. Godek (1981) Characterization of a calcium-activated proteinase that hydrolyzes a microtubule-associated protein. Arch. Biochem. Biophys. 208: 520-527.

Lazarides, E., and W. J. Nelson (1982) Expression of spectrin in nonerythroid cells. Cell 31 : 505-508.

Lazarides, E., and W. J. Nelson (1983a) Erythrocyte and brain forms of spectrin in cerebellum: Distinct membrane-cytoskeletal domains in neurons. Science 220: 1295-1296.

Lazarides, E., and W. J. Nelson (1983b) Erythrocyte form of spectrin in cerebellum: Appearance at a specific stage in the terminal differcntiation of ncurons. Scicnce 222: 931-933.

Lazarides, E., W. J. Nelson, and T. Kasamatsu (1984) Segregation of two spectrin forms in the chicken optic system: A mechanism for establishing restricted membrane-cytoskeletal domains in neurons. Cell 36: 269-278.

Levine, J., and M. Willard (1981) Fodrin: Axonally transported polypeptides associated with the internal periphery of many cells. J. Cell Biol. 90: 631-643.

Marchesi, V. T. (1974) Isolation of spectrin from erythrocyte membranes. Methods Enzymol. 32: 275-277.

Mareck, A., A. Fellous, J. Francon, and J. Nunez (1980) Changes in composition and activity of microtubule-associated proteins during brain development. Nature 284: 353-355.

McWilliams, J. R., and G. Lynch (1983) Rate of synaptic replacement in denervated rat hippocampus declines precipitously from the juvenile period to adulthood. Science 221: 572-574.

Morrissey, J. H. (1981) Silver stain for proteins in polyacrylamide gels: A modified procedure with enhanced uniform sensitivity. Anal. Biochem. 117: 307-310.

Murachi, T. (1983) Calpain and calpastatin. Trends Biochem. Sci. 8: 167-169.

Shaw, G., and K. Weber (1982) Differential expression of neurofilament triplet proteins in brain development. Nature 298: 277-278.

Siman, R., M. Baudry, and G. Lynch (1983) Purification from synaptosomal plasma membranes of calpain $\mathrm{I}$, a thiol-protease activated by micromolar calcium concentrations. J. Neurochem. 41: 950-956.

Siman, R., M. Baudry, and G. Lynch (1984) Brain fodrin: Substrate for calpain I, and endogenous calcium-activated protease. Proc. Natl. Acad. Sci. USA 81: 3572-3576.

Siman, R., M. Baudry, and G. Lynch (1985) Regulation of glutamate receptor binding by the cytoskeletal protein fodrin. Nature $313: 225$ 228

Simonson, L., M. Baudry, R. Siman, and G. Lynch (1985) Regional distribution of soluble calcium-activated proteinase activity in neonatal and adult rat brain. Brain Res. 327: 153-159.

Stahli, C., V. Miggiano, J. Stocker, T. Staehelin, P. Haring, and B. Takacs (1983) Distinction of epitopes by monoclonal antibodies. Methods Enzymol. 92: 242-253.

Towbin, H., T. Staehelin, and J. Gordon (1979) Electrophoretic transfer of proteins from polyacrylamide gels to nitrocellulose sheets: Procedure and some applications. Proc. Natl. Acad. Sci. USA 76: 43504354.

Weber, K., G. Shaw, M. Osborn, E. Debus, and N. Geisler (1983) Neurofilaments, a subclass of intermediate filaments: Structure and expression. Cold Spring Harbor Symp. Quant. Biol. 48: 717-730.

Wuerker, R. B., and J. B. Kirkpatrick (1972) Neuronal microlubules, neurofilaments and microfilaments. Int. Rev. Cytol. 33: 45-75.

Zagon, I. S., P. J. McLaughlin, and S. R. Goodman (1984) Localization of spectrin in mammalian brain. J. Neurosci. 4: 3089-3100.

Zimmerman, U. J. P., and W. W. Schlaepfer (1982) Characterization of a brain calcium-activated protease that degrades neurofilament protein. Biochemistry 21: 3977-3983. 